INGENIERÍA INDUSTRIAL

\title{
Modelo de la programación de turnos de trabajo considerando el bienestar de los empleados de las clínicas
}

INDUSTRIAL ENGINEERING

\section{Modeling the labor scheduling problem considering well- being for the clinic's employees}

\author{
Juan P. Orejuela*§, Diana Peña*, Neptalí Bustamante** \\ *Escuela de Ingeniería Industrial y Estadística, Universidad del Valle, Cali, Colombia \\ Sjuan.orejuela@correounivalle.edu.co,*dianapena86@gmail.com, \\ *neptali_bustamante@coomeva.com.co
}

(Recibido: 27 de abril de 2011 - Aceptado: 07 de noviembre de 2013)

\begin{abstract}
Resumen
El problema de la programación de turnos de trabajo, consiste en programar el horario de trabajo o los turnos de los distintos empleados buscando la minimización de los costos asociados al personal, el cual es un problema NP-hard. En este artículo se presenta un modelo de programación lineal entera mixta aplicado a un caso real, el cual tiene como objetivo minimizar el costo laboral, cumplir con los requerimientos de demanda y establecer condiciones laborales adecuadas para los empleados mediante la incorporación de restricciones que garanticen bienestar, para así generar una asignación óptima de los turnos de trabajo de los fisioterapeutas en las áreas de cuidados intensivos e intermedios de una Clínica. Para esto, se definieron diferentes escenarios variando tanto el número de fisioterapeutas como la estructura del modelo, resultando así que el número apropiado de fisioterapeutas a programar en la Clínica es de 32, ya que satisface todos los requerimientos de demanda, la legislación laboral, y las necesidades de la empresa y de los empleados.
\end{abstract}

Palabras clave: asignación de fuerza de trabajo, asignación de turnos, problema de programación de trabajadores.

\begin{abstract}
The Labor Scheduling Problem consists of planning the shifts for the employees, and minimizing costs associated to the workforce, which is a NP-hard problem. This paper presents a mixed integer linear programming modelapplied to a real case, which minimizes labor costs, satisfies the requirements of demand and establishes adequate working conditions for employees by incorporating constraints that ensure well-being to generate an optimal assignment of physiotherapist shifts in the intensive and intermediate care areas in a Clinic.For this, different scenarios were defined by varying both the number of physiotherapists and the structure of the model, the result that the appropriate number of physiotherapists in the clinic schedule is 32 , since it satisfies the requirements of demand, employment law and the needs of the company and employees.
\end{abstract}

Keywords: laborscheduling problem, shift assignment, workforce scheduling. 


\section{Introduction}

The workforce is a key and limited resource, so it is important to use it efficiently. It is therefore necessary to carry out the analysis of staff requirements for the whole day, especially in service companies where there is a high variation in demand by time slots. At the same time has the optimal assignment of shifts and workloads to employees that covers the demand requirements maintains an adequate level of service to optimize available capacity usage and avoids the high costs of not having the appropriate number of employees to satisfy the demand or the poor utilization of this resource.

The Labor Scheduling Problem is a NP-hard problem due to its own nature and complexity, with many techniques used to approach it, thus it is a topic that is in constant evolution (Pacheco et al, 2003). Although the majority of approaches are heuristic and metaheuristic, for some cases the size of the problem allows the use of exact techniques solvable in an acceptable computational time.

Many researchers have often studied this problem in service industries such as airlines, hospitals, clinics and transportation companies, and they have developed different models using exact, heuristic and metaheuristic techniques (Ballesteros et al, 2007).

Dantzig was one of the first researchers to study the Labor Scheduling Problem for which he made a mathematical model that seeks to minimize the cost of having all employees covering all shifts, and satisfy the demand with enough workforce in all periods (Dantzig, 1954). Brusco and Jacobs proposed a new solution to the discontinuous labor tour scheduling problem where the objective was to minimize the number of full-time employees required to satisfy forecasted demand. They developed a simulated annealingmetaheuristic for solving the problem (Brusco et al, 1993).

In (Vasconcelos et al, 1995) the authors proposed a model to solve the problem of a public transport company in Portugal, using the structure of The Traveling Salesman Problem to find an optimal sequence including rest days,takingthat the optimal sequence was assigned to the workers and it included balanced rest periods between duties, which had different durations and could start and finish at different times. (Thompson, 1995) presented a daily and weekly New Formulation of Labor Scheduling Problem (NFLSP) which incorporates information on how changing the number of employees working in each planning period affects profits. In (Dowsland, 1997) the author addressed a labor scheduling problem of nurses in a hospital using Tabu search with strategic oscillation, with the principal objective was to guarantee the permanence of enough nurses at any time slots considering equal workloads, requests for days off and costs. In this paper the well-being of nurses is timidly considered in reference to the requests for days off,however, it was a positive aspect of the approach since it considered employee well-being. After that, in (Alvarez et al, 1997) the authors proposed a system that programs shifts by determining time of entry and exit of each worker during the planning horizon, taking into account workload at any given time, rest periods and changes in shifts.

In (Ramalhinho et al, 1998) studied the Labor scheduling problem for bus drivers through a robust and flexible method that minimized the total cost generated by the drivers considering overtime and nocturnal hours, changes in vehicles and relays, and the type of service. They proposed metaheuristics such as GRASP, Tabu Search and Genetic Algorithms, which can be applied to combinatorial optimization problems.(VandenBerghe, 2002) introduces a model for the practical rostering problem in Belgian hospitals. It is general enough to cope with the large set of constraints and to meet varying objectives encountered in practice, taking into account the fact that some constraints are easier to satisfy than others while allowing schedulers to control compensation of constraints in the model.

In (Pacheco et al, 2003) the authors studied the different metaheuristic strategies used for the 
labor scheduling problem such as Simulated Annealing, Tabu Search, Genetic Algorithms, Greedy Randomized Adaptive Search Procedure (GRASP), and Memetic Algorithms; they concluded that the best technique for this problem is Tabu Search because of the quality of the solution and its low computational time.

In (Burke et al, 2004) the authors discussed about nurse rostering within the global personnel scheduling problem in healthcare, they described and discuss solution approaches which span the interdisciplinary spectrum from operations research techniques to artificial intelligence methods.

Ernts et al. (2004) have recollected 700 references focused in the personal shift programmation, and have been classified depending of the problem type like "Crew Scheduling", "Tour Scheduling", "Flexible Demand", "Workforce Planning", "Crew Rostering", "Shift Scheduling", "Task Assignment" among other things, also depending of the application area like airlines, buses, railroads, mass transit, call centers, nurses among other and classified by the used methods for its solution like enumeration, artificial intelligence, heuristic construction, local search, AntColony Optimization (ACO), among others.

In (Bard et al, 2005) the authors present a new methodology for reactively scheduling nurses in light of shift-by-shift imbalances in supply and demand. The problem associated is formulated as an Integer Program (IP) and solved within a rolling horizon framework. (Gutjahret al, 2005) the authors proposed a model that aims to assure the number of nurses required by different hospitals, minimize the total cost through the implementation of assignment strategies and consider the nurse's own requirements by applying an Ant Colony Optimization (ACO) methodology. In this study, the well-being of nurses is represented by an interesting approach that gives them the ability to set some preferences.

Later (Thompson et al, 2007) considered periods of rest, which use the representation made by
Dantzig in 1954 incorporating binary variables that represented rest periods. (Naidu et al, 2008) presents a literature review of the current state of staff scheduling, in particular nurse scheduling. In current health care service, the critical problem in nurse scheduling in a hospital is how to determine day-to-day shift assignments of each nurse for a period of time in a way that satisfies the given requirements of a hospital

The goal in (Kundu et al, 2008) is to find high quality shift and resource assignments, in accordance with the labor contract rules, satisfying the requirements of employees as well as the employers in health-care institutions. In (Castillo et al, 2009) proposed a multiobjective model that simultaneously considered the minimization of labor costs and maximization of service quality. (Burke et al, 2010) presents a hybrid multi-objective model that combines integer programming (IP) and variable neighborhood search (VNS) to deal with highly-constrained nurse rostering problems in modern hospital environments.

Instead (Topaloglu et al, 2010) the authors presented a seminal research on the application of fuzzy set theory to the nurse scheduling problem (NSP) to treat uncertainties in the target values of the hospital management and nurses' preferences.

For instance, (Cobes et al, 1991), (Bard et al, 2005), and (Quinteros et al, 2006) presented a mixed integer linear programming models solved within a reasonable computational time and their total amount of variables represent a complexity similar to the complexity of the model presented in this paper.

In this document, we proposed a mixed integer linear programming model for the optimal assignation of the work shift applied to a real case of physiotherapists in the intensive and intermediate care area in a clinic. The objective function is to minimize the labor cost, meet the customer demand and assure adequate labor conditions. 
In this document, we will be describing first the Labor Scheduling Problem, defining each of the involved factors. Later, we will be proposed a mixed integer linear programming model, its application and validation in a real case study, its results and its sensitivity analysis.

\section{Labor scheduling problem}

The Labor Scheduling Problem involves various factors such as the company, employees, demand requirements and Legislation,schedule, so it is necessary to consider them and achieve a balance between these factors.

Schedule In many companies, the basic unit for measuring time is"shift" thatis defined as a set of workedhours; each shift has the same amount of hours. The overtime is defined as complementary time in a shift, the working days are seven in the week.

Company Currently, many companies in their quest to achieve objectives and to adapt capacity to demand, have made an unequal distribution of time among temporary and part-time contracts, thus increasing the expansion and variability of shifts (Thompson et al, 2005).

Employees Employees have individual needs, wishes and preferences to execute their jobs efficiently, e.g. the need to rest, the desire to avoid consecutive night shifts or adjust to shift changes that affect their health, safety, family and social life. We must also have equity in workload and compensation between employees.

Demand Requirements Each area of a company has different requirements with regard to the number of employees per shift, their skills, competencies and working hours. Therefore, a company must establish a balance in the assignment of shifts to the employees taking into account their skills and availability.

Legislation and regulations The Legislation and regulations provide guidelines to control employer-employee interactions with regard to type of work, shift duration, spacing of breaks and workload. For the specific case of Colombia, these factors are mostly found in (Delgado, 2009).

\subsection{The problem}

When the service companies put in first place to its employees and customers, radical change occurs in the way in which manage and measure success by involving the profits, customer satisfaction and loyalty to the value of the services created by employees satisfied, loyal and productive. When employers decide to invest in people, technology support to their employees, the renewal of recruitment, training, and compensation practices related to employee's performance at all levels and well being of them is reflected in factors that generate profits.

This paper studied the shift programming in a health care industry (clinic), specifically the intensive care unit (ICU) and intermediate care area (IC), which seeks to maintain a service level that satisfies $100 \%$ of the demand, because these areas are critical due to situations where the patient's life is at risk. These areas have demand requirements, employee's needs and wishes to represent their well-being, because the practice of health care employees involves interaction with patients or clients, families, suppliers and health communities involves a duty cycle which begins with the point of initial contact with the client and proceeds through steps or stages until completion of all the service, along this cycle presents many moments of truth that define the service provided. A bad moment of truth can cancel many positives, even when given a service recovery.

For that, we defined the requirements of demand of this clinic, which involves a number permanent of beds and employees assigned to satisfy the needs of the patients, and the particular requirements for employee's needs and wishes to represent their well-being, which acquires great relevancy in service industries where the service level is directly related to employee well-being. These requirements are the following: 
- $\quad$ Provide a weekend off with pay in each 31 day period for each employee.

- Assure that employees ending a night shift are not scheduled for the next day.

- Distribute the workload equitable among employees.

- In relation to staff skills and competencies of the employees, it is necessary to have professionals trained in physical therapy, intensive care, use of mechanical ventilators, advanced air passage skills, and the ability to manage critical situations ably and quickly.

- To determine labor costs, it is necessary to consider the base salary (regular hour cost), recruitment costs, additional charges related with the number of hours worked (overtime cost), and the cost of programming a physiotherapist. The costing of regular and overtime hours is calculated for a week, and it is the same for all the weeks in a month. It is assumed there are no holidays in the month.

- The legislation sets the maximum duration of the normal working day at eight (8) hours with a forty-eight (48) hours week. Daytime and nighttime over-time may not exceed two (2) hours daily and twelve (12) hours weekly. Night, holiday and overtime surcharges have been included in the remuneration.

- Therefore, the clinic has three shifts of eight hours to comply with the balance in hours worked and the maximum legal duration of each shift.

\section{Solution methodology}

We propose the following mixed integer linear programming model for the assignment of shifts within a time horizon:

\subsection{Notation and Definition}

\section{Sets and indexes}

$\mathbf{E}=$ Set of employees with index $e, e \in\{1, \ldots, E\}$
$\mathbf{T}=$ Set of shifts with index $t, t \in\{1, \ldots, T\}$

$\mathbf{W}=$ Set of weeks with index $s, s \in\{1, \ldots, W\}$

$\mathbf{D}=$ Set of days with index $d, d \in\{1, \ldots, D\}$

$\mathbf{L}=$ Set of locations with index $l, l \in\{1, \ldots, L\}$

$\mathbf{R}=$ Set of demand requirements with index $r, r \in\{1, \ldots, R\}$

LR [I] = Induced set representing the demand requirements $r$ for each location 1 .

\section{Parameters}

$\mathbf{c t}_{\mathbf{t d}}=$ Cost of a regular hour associated to shift $t$ on day $d$.

cte $_{\text {td }}=$ Cost of an over-time hour associated to shift $t$ on day $d$.

$\mathbf{c a}_{\mathbf{e}}=$ Cost of monthly salary for an employee $e$.

xini $_{\text {etlr }}=$ Binary parameter that indicates the initial programming of employee $e$ in shift $t$ at location 1 to satisfy requirement $r$ on day 0 . If the employee is not scheduled for day 0 , all parameter values are 0 .

$\mathbf{n z}=$ Number of requirements to be covered to satisfy demand in a month.

$\mathbf{n h}=$ Number of hours in a shift.

ntr $=$ Number of shifts in which the maximum regular hours are completed in a week.

mn =Maximum number of night shifts for an employee during the week.

$\mathbf{m e}=$ Maximum number of shifts in a week in which overtime is allowed.

tn =Night Shift

\section{Variables}

$\mathrm{K}=$ Continuous variable that represents the salary increment above the payment base; this variable is used to balance employee salaries

\section{The model}

Minimize Cost $=$ Regular hour Cost + Overtime Cost + Wage Cost + Cost increase over regular time for the best paid employee. 
$\mathrm{X}_{\text {etlrsd }}\left\{\begin{array}{l}1, \text { if employee e works regular hours in shift } \mathrm{t} \\ \text { at location } 1 \text { to satisfy demand requirement } \mathrm{r} \text { in } \\ \text { week s on day d. } 0 \text { otherwise }\end{array}\right.$

$\mathrm{Y}_{\text {ettrsd }}\left\{\begin{array}{l}1, \text { if employee e works overtime hours in shift } \mathrm{t} \\ \text { at location } 1 \text { to satisfy demand requirement } \mathrm{r} \text { in } \\ \text { week s on day d. } 0 \text { otherwise }\end{array}\right.$

$\mathrm{Z}_{\mathrm{e}}\left\{\begin{array}{l}1, \text { if employee e is scheduled to work. } 0 \\ \text { otherwise }\end{array}\right.$

$\mathrm{S}_{\mathrm{es}}\left\{\begin{array}{l}1, \text { if employee e is scheduled to work on week } \\ \text { s. } 0 \text { otherwise. }\end{array}\right.$

In the objective function, part (1) estimates the total shifts assigned to each employee (sum of $X_{\text {etrrsd }}$, which multiplied by the number of hours of each shift generates the number of hours worked by each employee. These hours multiplied by the cost of regular time totals the cost associated with regular hours worked by all employees. Part (2) calculates the cost associated with overtime shifts. Component (3) is the cost generated by one employees' wages when this employee is included in the scheduling. Balance variable Kin (4) takes the value of the best paid employee and sets this value as the remuneration limit to achieve balance by minimizing this value using the objective function.

The constraints for the model are: Constraint (5) assures that the limit of regular shifts is not

$$
\begin{aligned}
& \operatorname{Min} \sum_{e \in E} \sum_{t \in S} \sum_{l \in L} \sum_{r \in L R[1]} \sum_{s \in W} \sum_{d \in D}\left(n h \times X_{\text {ettrsd }} \times c t_{t d}\right) \\
& +\sum_{e \in E} \sum_{t \in S} \sum_{l \in L} \sum_{r \in L R[1]} \sum_{s \in W} \sum_{d \in D}\left(n h \times Y_{\text {ettrs }} \times \text { cte }_{t d}\right) \\
& +\sum_{e \in E} c a_{e} \times Z_{e} \\
& +K \\
& \sum_{t \in S} \sum_{l \in L} \sum_{r \in L R[1]} \sum_{d \in D}\left(X_{\text {ettrsd }}\right) \leq n t r \forall e \in E, s \in W \\
& n t r \times Y_{\text {ettrsd }} \leq \sum_{t^{\prime} \in S} \sum_{l^{\prime} \in L} \sum_{r^{\prime} \in L R[1]} \sum_{d^{\prime} \in D}^{d^{\prime}<d} X_{\text {ett' }{ }^{\prime} r^{\prime} s^{\prime} d^{\prime}} \forall e \in E, t \in S, r \in L R[1], s \in W, d \in D \\
& \sum_{e \in E}\left(X_{\text {ettrsd }}+Y_{\text {ettrsd }}\right)=1 \forall t \in S, l \in L, r \in L R[1], s \in W, d \in D \\
& \sum_{t \in S} \sum_{l \in L} \sum_{r \in L R[1]}\left(\left(X_{\text {ettrsd }}\right)+\left(Y_{\text {etrrs }}\right)\right)+\sum_{t^{\prime} \in S \mid t=t h} \sum_{l^{\prime} \in L} \sum_{\left.r^{\prime} \in L R^{\prime} \mid 1\right]}\left(\text { xini }_{\text {ettrr }}\right) \leq 1 \forall e \in E, s \in W, d \in D \mid s=1, d=1
\end{aligned}
$$

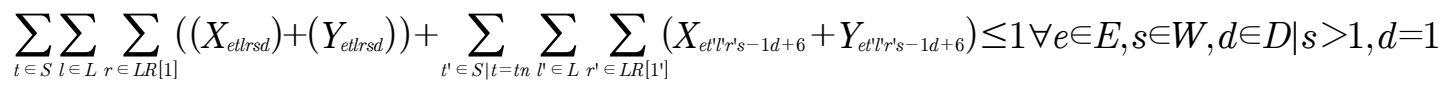

$$
\begin{aligned}
& \sum_{t \in S} \sum_{l \in L} \sum_{r \in L R[1]}\left(\left(X_{\text {ettrsd }}\right)+\left(Y_{\text {ettrsd }}\right)\right)+\sum_{t^{\prime} \in S \mid t=t n} \sum_{l^{\prime} \in L} \sum_{r^{\prime} \in L R\left[1^{\prime}\right]}\left(X_{\text {ett } r^{\prime} r^{\prime}-1}+Y_{\text {ett } r^{\prime} r^{\prime}-1}\right) \leq 1 \forall e \in E, s \in W, d \in D \mid s \geq 1, d>1 \\
& \sum_{t \in s} \sum_{l \in L} \sum_{r \in L R[1]} \sum_{s \in W} \sum_{d \in D}\left(\left(X_{\text {ettrsd }}\right)+\left(Y_{\text {ettrsd }}\right)\right) \leq n z \times Z_{e} \forall e \in E \\
& \sum_{t \in s} \sum_{l \in L} \sum_{r \in L R[1]} \sum_{s \in W} \sum_{d \in D}\left(\left(X_{\text {ettrsd }}\right)+\left(Y_{\text {ettrsd }}\right)\right) \leq m n \forall e \in E, s \in W \\
& \sum_{t \in s} \sum_{l \in L} \sum_{r \in L R[1]} \sum_{s \in W} \sum_{d \in D}\left(Y_{\text {ettrsd }}\right) \leq m e \forall e \in E, s \in W
\end{aligned}
$$




$$
\begin{gathered}
\sum_{t \in s} \sum_{l \in L} \sum_{r \in L R[1]} \sum_{s \in W} \sum_{d \in D} n h \times\left(X_{\text {ettrsd }} \times c t_{t d}+Y_{\text {ettrs }} \times c t e_{t d}\right) \leq K \forall e \in E \\
S_{e s} \times 2 \geq \sum_{t \in s} \sum_{l \in L} \sum_{r \in L R[1]} \sum_{s \in W} \sum_{d \in D}\left(\left(X_{\text {ettrsd }}\right)+\left(Y_{\text {ettrsd }}\right)\right) \forall e \in E, s \in W \\
\sum_{s \in W} S_{e s} \geq 3 \forall e \in E \quad \text { (16) } \\
X_{\text {ettrsd }}, Y_{\text {ettrsd }}, Z_{e}, S_{e s} \in \text { Binary }\{0,1\} \quad K=\text { Continous }
\end{gathered}
$$

exceeded; once it completes this limit, constraint (6) is activated i.e. overtime is activated. (7) aims to satisfy the demand and exclusion among the regular and overtime hours. Constraints (8), (9) and (10) are related to shift changes. In (8) when an employee works the night shift in the initial programming, this employee is not programmed the next day. In (9) when $S>1$, the last day of the previous week is taken as a reference to schedule the employee in the following week's shifts. And (10) where $S>=1$ and $S>1$, the previous day is taken as a reference.

Constraint (11) assures that only scheduled employees are assigned. Then (12) seeks to balance the night shifts between employees, establishing a limit for night shifts in a week and (13) establishes a maximum number of overtime shifts during the week according to the legislation. Constraint (14) balances employee's remuneration since $K$ is being minimized in the objective function. In constraints (15) and (16), the $\mathrm{S}$ variable is activated when an employee works at least one day on a weekend, and it must be less than or equal to 3 , allowing employee e to have at least one weekend off during the four weekends in a month.

\section{Application and validation of the model}

For theimplementation of the model, the following parameters and assumptions are defined with the information provided by the Clinic:

The current number of physiotherapists in the clinic is 24 , which works 3 shifts.

There are 2 locations, which correspond to theintensive care area and intermediate care area.
The intensive care area has 6 different demand requirements, and the intermediate care area has 2 .

The number of jobs to meet the demand for a month in the 2 areas is 504 .

Each shift has 6 hours, and the allowed maximum working hours per week are 48 .

The allowed maximum numbers of night shifts per physiotherapist is 3 . The allowed maximum numbers of overtime shifts per physiotherapist in a week is 1 .

Exist an initial programation at the firts day.

Labor scheduling will be done for a 28 day month. Specifically, it has 7 days in each of the 4 weeks and there are no holidays.

The basic salary for each physiotherapist is COP\$ $1,950,000$, i.e. they all have the same salary.

It is assumed that the employees' level of responsibility assures compliance with their assignments and that during the whole month there will be no employee absenteeism or desertion.

Another parameters are the cost associated with worked hours, overworking hours and its surcharge, and the cost of program a physiotherapist.

Worked hours cost: To calculate the worked hours cost, it is assumed that this is included in the base salary. Therefore, the regular hours only includes the night, overworked and holyday surcharges. 
Overworked hours cost: The calculation of overtime is performed on the base salary, because it includes the overworking hours. The day overwork is paid with a $25 \%$ surcharge over the regular day value and the night overwork is paid with a $75 \%$ surcharge over the regular day value.

The calculations of the worked and overworked hours are made by a period of a week, and it is assumed that doesn't exist holidays.

Cost of program a physiotherapist: To calculate this cost, it is taken into account the social contributions, vacations and redundancy payment earned by the physiotherapist.

The model was implemented in the AMPL programming language and the computational tool used was: CPLEX ${ }^{\circledR}$ 11.1. During the implementation, the different versions that were developed had the behaviors shown in Table 1.

The runs of the model showed a high level of computational complexity. The resolution time was approximately 2 hours or more and this occurred due to its large size and the high number of binary variables.

Table 1. Implementation of the versions

\begin{tabular}{cccc}
\hline Version & \multicolumn{2}{c}{$\boldsymbol{N}^{\circ}$ Variables } & $\begin{array}{c}\boldsymbol{N}^{\circ} \\
\text { Constraints }\end{array}$ \\
& Binaries & Continuous & \\
\hline $\mathrm{e}=32$ & 29,896 & 1 & 15,718 \\
$\mathrm{e}=24$ & 22,369 & 1 & 11,886 \\
without free \\
$\begin{array}{c}\text { weekend } \\
\mathrm{e}=24 \text { only } \\
\text { assignment }\end{array}$ & 22,488 & 0 & \\
\hline
\end{tabular}

\section{Results and discussion}

First, the proposed model was implemented for the 24 physiotherapists presently at the clinic. Once the results were obtained, it was observed that the model did not generate a feasible solution since the current number of employees satisfies the demand requirements but does not satisfy the constraints that assure well-being of the physiotherapists.

Subsequently, several runs of the model were done changing the number of programmed physiotherapists, and it was found that 32 is the appropriate number because it satisfies all requirements for all locations in all shifts. The 32 physiotherapists satisfied all the constraints defined in the model, including the well-being's constraints and it generated an optimal schedule. This solution has an objective function value of COP $\$ 104,215,416$.

As shown in Table 2, the model assigned regular hours but no overtime because the number of regular hours that 32 physiotherapists can offer is 6,144 hours per month, which exceeds the 4,032 hours required to satisfy the 504 demand requirements for all locations within a month. Therefore, the model did not incur overtime cost $\left(c_{t e}\right)$; it only generated the fixed cost $\left(c_{t d}\right)$ which corresponds to the 4,032 regular hours per month (COP\$9,165,312). It can be observed in the hours distribution, the model only assigned regulars hours, from which $57 \%$ are daytime hours, $29 \%$ are nighttime hours, $10 \%$ are dominical daytime hours and $5 \%$ are dominical nighttime hours. This is because there are two daytime shifts and one nighttime shift.

Table 2. Number of hours worked.

\begin{tabular}{ccc}
\hline Type & Day & Night \\
\hline Regular & 2304 & 1152 \\
Overtime & 0 & 0 \\
Regular Sunday & 384 & 192 \\
Overtime Sunday & 0 & 0 \\
Total Hours & 2688 & 1344 \\
\hline
\end{tabular}

In the following, we present the number of hours worked by 32 physiotherapists in a month, depending on the type of shift to satisfy the demand in Table 3. Also shown are the most relevant for the different versions in the two scenarios presented for the analysis of results.

The cost to the company for programming 32 physiotherapists working regular hours is 
Ingeniería y Competitividad, Volumen 16, No. 1, p. 11 - 21 (2014)

Table 3. Sensitivity and change of structure analysis summary.

\begin{tabular}{|c|c|c|c|c|c|c|c|c|c|}
\hline & & \multicolumn{4}{|c|}{ Objetive Function (COP \$) } & \multirow{2}{*}{$\begin{array}{c}\text { Total Cost } \\
\text { (COP \$) }\end{array}$} & \multirow{2}{*}{$\begin{array}{c}\% \\
\text { Utilization }\end{array}$} & \multirow{2}{*}{$\begin{array}{c}\text { Mean K } \\
\text { (COP \$) }\end{array}$} & \multirow{2}{*}{$\begin{array}{l}\text { Average } \\
\text { Deviation }\end{array}$} \\
\hline & & $C T$ & $C T E$ & $\boldsymbol{C A}$ & $\boldsymbol{K} \boldsymbol{M A X}$ & & & & \\
\hline \multicolumn{2}{|c|}{32 Employees } & $9,165,312$ & 0 & $94,753,536$ & 296,568 & $104,215,416$ & $65.63 \%$ & 286,416 & $5.89 \%$ \\
\hline \multirow{3}{*}{ 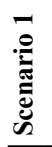 } & $\mathrm{ca}$ & $9,165,312$ & 0 & $71,065,152$ & 385,944 & $80,616,408$ & $87.50 \%$ & 381,888 & $0.70 \%$ \\
\hline & $0 *$ ca & $9,165,312$ & 0 & 0 & 381,888 & $9,547,200$ & $87.50 \%$ & 381,888 & $0.00 \%$ \\
\hline & $2 * \mathrm{ca}$ & $9,165,312$ & 0 & $142,130,280$ & 385,944 & $151,681,536$ & $87.50 \%$ & 381,888 & $0.94 \%$ \\
\hline 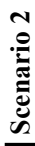 & $\begin{array}{c}\text { Only } \\
\text { Assigment }\end{array}$ & $6,240,384$ & $32,905,728$ & $26,649,432$ & $\mathrm{n} / \mathrm{a}$ & $65,795,544$ & $233.33 \%$ & $4,349,568$ & $60.93 \%$ \\
\hline
\end{tabular}

COP\$94,753,536, which varies depending on the number of physiotherapists that are programmed; the fixed cost per physiotherapist is COP $\$ 2,961,048$. The bestpaidphysiotherapist, cost $k$, for the 32 physiotherapists was COP\$296,568, which includes the cost of working hours and surcharges in a month. This cost together with the fixed cost for one physiotherapist represents the maximum total cost paid to one physiotherapist of COP $\$ 3,257,616$, with an average deviation of $5.89 \%$ which is reflected in the total cost balance.

Regarding the physiotherapist utilization, we concluded that to cover the 504 demand requirements in a month, the clinic has an supply of 32 physiotherapist that represent a theoretical capacity of 768 shifts per month. This capacity is limited by well-being constraints defined in the model. As to the weekend off constraint, it represents a decrease of 32 shifts per month because each physiotherapist has a weekend off in one month, implying that in a week one physiotherapist cannot work 6 regular shifts, only 5. Thus one shift per physiotherapist is lost in a month. In addition, 8 physiotherapists will be off every weekend of the month.

The night shift constraint represent a reduction of 40 shifts per month, since each physiotherapist must have a day off after working a night shift, and in a month there must be 168 night shifts to satisfy the requirements of each location. Thus 42 night shifts per week must be covered with the 32 physiotherapists meaning that only 32 shifts can be covered and the remaining 10 shifts need to be distributed among physiotherapists who have already been assigned shifts, so one physiotherapist in a week is assigned 2 night shifts. This implies that he/she has 2 days off each week, setting a 5 shift work week for this physiotherapist, which is one shift short of the 48 regular hours per week in 6 shifts.

Finally, assigning just one shift to one physiotherapist in the day also represents a decrease. Therefore, the reductions generated by these constraints represent a $65.62 \%$ utilization of the physiotherapists.

After analyze the study case and the different scenarios of the Table 3, it is concluded that in this cases, the decision of the workforce that include the wellbeing of the employees, is a decision that should made with the employee and the employer together, that is because the different factors that affect the well being of the employee, generates a cost to both parts, for the company, the cost for wage compensation increases, this is due to the increase in the number of employees to assign, and the decrease in the workforce. For the employees topic, they will receive a smaller salary, to compensate for free weekends.

\section{Sensitivity and change of structure analysis.}

Two scenarios with changes in the structure of the model and with variations in the number of physiotherapists were defined. The first scenario 
excluded the constraint which guarantees one weekend off per month for 24 physiotherapists, leading to a variation in the cost of programming. In the second one, all constraints were omitted except the one which guaranteed assignment of physiotherapists to the different requirements.

\section{References}

Álvarez, R., Crespo, E. \& Tamarit, J.M. (1998). Organización de turnos de trabajo en una instalación de suministro de combustible de un aeropuerto. VI Jornadas ASEPUMA, Universitat de València, Santiago de Compostela, España, p. 1-7.

Ballesteros, D. \& Ballesteros, P. (2007). Algunos modelos para planeación y programación en empresas de servicios. Scientia et Technica XIII (34), 315-320.

Bard, J. F. \& Purnomo, H. W. (2005). Hospitalwide reactive scheduling of nurses with preference considerations. IIE Transactions 37 (7), 589-608.

Brusco, M. \& Jacobs, L. (1993).A Simulated Annealing Approach to the Solution of Flexible Labour Scheduling Problems. The Journal of the Operational Research Society 44 (12), 1191-1200.

Burke, E. K. Li, J. \& Qu, R. (2010). A hybrid model of integer programming and variable neighbourhood search for highly-constrained nurse rostering problems. European Journal of Operational Research 203 (2), 484-493.

Burke, E., De Causmaecker, P., VandenBerghe, G. \& Van Landeghem, H. (2004). The State of the Art of Nurse Rostering. Journal of Scheduling 7(6), 441-499.

Castillo, I., Joro, T. \& Li, Y. (2009). Workforce scheduling with multiple objectives. European Journal of Operational Research. 196 (1), 162170.

Cobes, A. \& Companys, R. (1991). Modelo de localización de servicios de extinción de incendios. Questiio: Quaderns d'Estadistica,
Sistemes, Informatica ilnvestigació Operativa. 15 (2), 199-210.

Dantzig, G. (1954). A comment on Edie's traffic delays at toll booths. Journal of the Operations Research Society of America. 2 (3), 339-341.

Delgado, C. (2009). Código sustantivo del trabajo y código procesal del trabajo y de la seguridad social. Bogotá: Legis.

Dowsland, K.A. (1997). Nurse scheduling with tabu search and strategic oscillation. European Journal of Operational Research 106 (2-3), 393407.

Ernst, A., Hiang, H., Krishnamoorthy, M., Owens, B., \& Sier, D. (2004).An Annotated Bibliography of Personnel Scheduling and Rostering. Annals of Operations Research, 127, 21-144.

Gutjahr, W.J. \& Rauner, M.S. (2007).An ACO algorithm for a dynamic regional nurse-scheduling problem in Austria. Computers \& Operations Research 34 (3), 642-666.

Kundu, S., Mahato, M., Mahanty, B. \& Acharyya, S. (2008). Comparative Performance of Simulated Annealing and Genetic Algorithm in Solving Nurse Scheduling Problem. In Proceedings of the International MultiConference of Engineers and Computer Scientists, Hong Kong. China, p. 19-21.

Naidu, K. D., Sullivan K. M., Wang, K. M. \& Yang, Y. (2008). Managing Personnel through Staff Scheduling Algorithms. CiteSeerX Scientific Literature Digital Library and Search Engine, p. 1-7.

Pacheco, J.A. \& Casado, S. (2003). Estudio comparativo de diferentes estrategias metaheurísticas para la resolución del Labor Scheduling Problem. Estudios de Economía Aplicada 21(3), 537-557.

Quinteros, M., Alonso, A., Escudero, L., Guignard, M. \& Weintraub, A. (2006). Una aplicación de 
programación estocástica en un problema de gestión forestal. Revista Ingeniería de Sistemas, $\mathrm{XX}, 67-95$.

Ramalhinho, H., Pinto, J. \& Portugal, R. (1998). Metaheuristics for the Bus-Driver Scheduling Problem. Department of Economics and Management, Universitat Pompeu Fabra 304, $1-26$.

Thompson, G. (1995). Labor scheduling using NPV estimates of the marginal benefit of additional labor capacity. Journal of Operations Management 13(1), 67-86.

Thompson, G. \& Pullman, M. (2007). Scheduling workforce relief breaks in advance versus in real- time. European Journal of Operational Research 181(1), 139-155.

Topaloglu S. \& Selim H. (2010).Nurse scheduling using fuzzy modeling approach. Fuzzy Sets and Systems 161(11), 1543-1563.

VandenBerghe, G. (2002). An Advanced Model and Novel Meta-heuristic Solution Methods to Personnel Scheduling in Healthcare. Doctoral Thesis. Universiteit Ghent, Ghent, Bélgica.

Vasconcelos, J. \& Campos, R. (1995). A Travelling Salesman Model for the Sequencing of Duties in Bus Crew Rotas. The Journal of the Operational Research Society 46 (4), 415- 426. 